\title{
Anorectal malformation: familial aspects and associated anomalies
}

\author{
G R BOOCOCK AND D DONNAI
}

Booth Hall Children's Hospital and Department of Medical Genetics, St Mary's Hospital, Manchester

SUMMARY One hundred and sixty nine patients with anorectal malformation were studied: there were 108 boys, 60 girls, and one case of intersex. Low malformations were more common in both sexes. Over half the subjects had associated malformations. These were more common in the group with high malformations. There was no difference between the sexes in this respect. A family history of similar malformation was found in 15 cases $(9 \%)$. Where anorectal malformation was the only abnormality in the family an autosomal dominant mode of inheritance was likely, except in one case where there was consanguinity. Where there were associated malformations no single mode of inheritance emerged. Two families with probably hitherto unrecognised recessive syndromes are described. In most cases of anorectal malformation the recurrence risk is low. Multiple associated malformations may indicate recessive inheritance and subsequent pregnancies should be regarded as high risk and full antenatal investigative facilities provided.

Anorectal malformations (ARM) are common, occurring in about one in 5000 births. ${ }^{1}$ There is wide variation in the type of malformation and the range of associated abnormalities. ${ }^{2}$ There are many published reports of single family studies, and all forms of Mendelian inheritance have been described. Other authors have looked at the prevalence of associated abnormalities in subjects and their families and have described various syndromes and associations. Most of these reports are on small study samples and their value to the genetic counsellor is limited.

The object of this retrospective study was to ascertain all live births of infants with ARM during an eight year period in the north west of England. Notes were examined to discover what proportion had other malformations and which body systems were most commonly affected. Note was made of any family history of similar abnormality. The information was analysed to identify possible syndromal associations and patterns of inheritance that might allow more accurate estimation of recurrence risk.

\section{Patients and methods}

Details of all infants with ARM admitted to the regional neonatal surgical centres between 1974 and 1981 inclusive were obtained from the hospital activity analysis, backed up by surgical registers. The regional computer records were studied to pick up early neonatal deaths and minor abnormalities that had not been referred to the regional centres. Unfortunately, because of the large number of hospitals involved and incomplete records it was not possible to trace stillbirths with ARM. The case notes of every child were studied and the infant's medical and family details extracted. Cases were sorted on the basis of sex and divided into high and low type of ARM as defined by Wilkinson. ${ }^{3}$ They were also grouped according to whether the ARM was the only abnormality (isolated group) or whether there were congenital abnormalities that affected other body systems (multiple group). The groups were compared using the $\chi^{2}$ test. If other affected family members were mentioned the medical records of the relatives were obtained where possible.

\section{Results}

A total of 169 cases was identified, of which 28 $(17 \%)$ had died by the time of study. Two of these deaths were unrelated to the congenital abnormality. (One drowned at the age of 3 years 11 months and the other was a cot death at 3 months with no cause found at postmortem examination.)

There were 108 boys (64\%) and 60 girls (36\%) 
plus one case of intersex (karyotype not known). The relative numbers of high and low malformations and their relation to sex is shown in Table 1 .

In 80 cases $(47 \%)$ the ARM was the only abnormality recorded. Of these, $48(60 \%)$ were boys and $32(40 \%)$ girls. In 67 of these 80 cases $(84 \%)$ the abnormality was of the low type and in 13 $(16 \%)$ of the high type.

Five of the isolated group had a family history of ARM. In three of these the propositus was a boy and the father had an ARM. The fourth case with a positive family history was also a boy, with an affected half brother. In the fifth case the propositus was a girl whose parents were consanguineous and whose first cousin also had an ARM. In all cases except the girl the ARM were of the low type.

In 88 cases the ARM was associated with other abnormalities (multiple group). This group showed a more pronounced preponderance of boys ( 60 boys $(68 \%) v 28$ girls $(32 \%))$, although the difference in sex distribution between multiple and isolated groups was not significant $(p>0 \cdot 05)$.

The proportion of high ARM was greater in the multiple group $(58 \%, \mathrm{p}<0.01)$. Altogether, $80 \%$ of infants with a high ARM had other malformations compared with $36 \%$ of those with a low ARM. The distribution of the type of associated abnormalities for the group as a whole and for each sex is shown in Table 2.

Table 1 No of high and low anorectal malformations in 169 patients according to sex

\begin{tabular}{lclc}
\hline & $(n)$ & \multicolumn{2}{l}{ No $(\%)$ of anorectal malformations } \\
\cline { 3 - 4 } & & High & Low \\
\hline Boys & $(108)$ & $47(44)$ & $61(56)$ \\
Girls & $(60)$ & $17(28)$ & $43(72)$ \\
\hline Total & $(169)^{*}$ & $65^{*}(38)$ & $104(62)$ \\
\hline
\end{tabular}

${ }^{*}$ One intersex case.
Ten infants with multiple abnormalities had a family history of ARM. There was an equal number of high and low ARM and a boy:girl ratio of 7:3. Full details are shown in Table 3.

There were six cases of consanguinity, five of whom were boys and one girl. In every case the parents were first or second cousins and were of Asian origin.

Several cases fitted the pattern of recognised syndromes or associations: Pfeiffer's syndrome, Frazer's syndrome, Downs' syndrome (three cases), $\mathrm{C}$ syndrome, fragile $\mathrm{X}$ syndrome, omphalocoele, extrophy of the bladder, imperforate anus, and spinal defect complex, and vertebral defects, imperforate anus, tracheo-oesophageal fistula, and radial and renal dysplasia association (eight cases). Note was made of any possible teratogens. A wide variety of drugs had been taken in the pregnancies but in only one case was there possible teratogenicity, this being in a mother who had taken Tridione throughout her pregnancy. One mother had been exposed to rubella in early pregnancy but congenital infection was not proved. Two mothers had diabetes.

\section{Discussion}

This study shows that low ARM are more common than high ARM and suggests that the incidence is greater in boys than in girls. This is in keeping with the findings of other workers. ${ }^{4}$ When analysed this male predominance seemed to relate mainly to the group with high ARM, $73 \%$ of which were boys compared with $59 \%$ in the group with low ARM. This apparent male predominance in the group with high ARM did not quite reach significance $(p>0.05)$. It has been suggested that the greater incidence of high ARM in boys is due to the influence of the development of the müllerian system between the alimentary and urinary systems in girls. ${ }^{4}$

Table 2 Distribution of associated abnormalities in 169 infants with high and low anorectal malformation. Values are No (\%)

\begin{tabular}{|c|c|c|c|c|c|c|}
\hline \multirow[t]{2}{*}{ System } & \multicolumn{2}{|l|}{ All cases } & \multicolumn{2}{|l|}{ Boys } & \multicolumn{2}{|l|}{ Girls } \\
\hline & High $(n=6.5)^{\text {* }}$ & Low $(n=104)$ & High $(n=47)$ & Low $(n=61)$ & High $(n=17)$ & Low $(n=43)$ \\
\hline Genitourinary tract & $39(60)$ & $28(37)$ & $25(53)$ & $15(25)$ & $14(82)$ & $12(28)$ \\
\hline Skeletal & $20(31)$ & $15(14)$ & $13(28)$ & $10(16)$ & 7 (41) & $5(12)$ \\
\hline Cardiovascular & $14(22)$ & $10(10)$ & $12(26)$ & $5 \quad(8)$ & $2(12)$ & $4(9)$ \\
\hline Facial & $13(20)$ & $10(10)$ & $9(19)$ & $5 \quad(8)$ & $4(24)$ & (9) \\
\hline Gastrointestinal & $22(34)$ & 0 & $16(33)$ & 0 & $6(35)$ & 0 \\
\hline Single umbilical artery & $8(12)$ & $1(1)$ & $4(9)$ & () & $4(24)$ & 0 \\
\hline Neurological & $2(3)$ & 3 (3) & 2 (4) & $2 \quad(3)$ & 0 & (2) \\
\hline Miscellaneous & $5 \quad(8)$ & 7 (7) & 3 (6) & $6(10)$ & $1 \quad(6)$ & 1 (2) \\
\hline
\end{tabular}

${ }^{*}$ One intersex case. 
Over half our subjects had associated abnormalities $(53 \%)$, but the incidence was greater in the group with high ARM (80\%), suggesting a more complex pathogenesis of high ARM.

Although multisystem involvement is slightly more common in boys than in girls $(56 \% \vee 47 \%)$, this could be accounted for by the greater proportion of high anomalies in boys - that is, given the presence of a high ARM, multiple abnormalities are as likely in a girl as in a boy. In both sexes the other body system most commonly affected was the genitourinary tract. This is probably due to the anatomical and temporal proximity of the embryological development of the lower bowel and genitourinary tract. The high incidence of skeletal, cardiovascular, and facial anomalies found is less easy to explain and implies an early and generalised insult with maximum effect on those systems that undergo most active transformation at the time. A possible insult was identified in only a few cases: in one case a drug (Tridione) was responsible and in four cases (three Down's and one fragile X syndromes) a chromosomal abnormality was responsible. The range of associated abnormalities was similar for both sexes and for the groups with high ARM and the group with low ARM, the only difference being that other gastrointestinal tract anomalies were only found in the group with high ARM. This may be because of the differing embryological origins of high and low ARM. ${ }^{4}$

One of the main aims of this study was to consider the familial nature of anorectal anomalies. Five examples of familial incidence were seen in the group with ARM only. In four of these the pattern was suggestive of an autosomal dominant mode of inheritance (Table 3, cases 1-5). In all cases within

Table 3 Congenital abnormalities recorded in families of children with anorectal malformations

\begin{tabular}{|c|c|c|c|c|c|}
\hline \multirow{2}{*}{$\begin{array}{l}\text { Case } \\
\text { No }\end{array}$} & \multirow[t]{2}{*}{ Sex } & \multirow{2}{*}{$\begin{array}{l}\text { Type } \\
\text { ARM }\end{array}$} & \multirow[t]{2}{*}{ Other abnormalities } & \multicolumn{2}{|l|}{ Other family cases } \\
\hline & & & & Affected member & Ahnormalities \\
\hline 1 & $\mathbf{M}$ & Low & - & Father & Imperforate anus \\
\hline 2 & $\mathbf{M}$ & Low & - & $\begin{array}{l}\text { Half brother } \\
\text { (paternal) }\end{array}$ & Anal stensosis \\
\hline 3 & $\mathbf{M}$ & Low & - & Father & Imperforate anus \\
\hline 4 & $\mathbf{M}$ & Low & - & Father & Imperforate anus \\
\hline 5 & $\mathrm{~F}$ & High & - & $\begin{array}{l}\text { Second } \\
\quad \text { cousin (?sex) }\end{array}$ & Imperforate anus \\
\hline 6 & $\mathbf{M}$ & Low & $\begin{array}{l}\text { Skeletal: Radial aplasia. } \\
\text { abnormal toes. } \\
\text { CVS: ASD. VSD. TGV. } \\
\text { third atrium. } \\
\text { GUT: Dysplastic kidneys. } \\
\text { Misc: Pulmonary hypoplasia }\end{array}$ & Sister & $\begin{array}{l}\text { Single (right) lower } \\
\text { limb. } \\
\text { abnormal forearm. } \\
\text { dysplastic kidneys. } \\
\text { imperforate anus } \\
\text { Anencephaly }\end{array}$ \\
\hline 7 & $\mathbf{M}$ & Low & GUT: Bilateral hydronephrosis & Siblings (?sex) & Conjoint twins \\
\hline 8 & $\mathbf{M}$ & High & $\begin{array}{l}\text { Skeletal: Abnormal vertebrae, } \\
\text { dysplastic foot. } \\
\text { CVS: Single ventricle, } \\
\text { ASD. single AV valve, } \\
\text { pulmonary atresia. } \\
\text { GIT: Asplenia }\end{array}$ & Sister & $\begin{array}{l}\text { Anal stenosis. } \\
\text { polydactyly. } \\
\text { single ventricle. } \\
\text { asplenia }\end{array}$ \\
\hline 9 & $\mathbf{M}$ & High & $\begin{array}{l}\text { Skeletal: Broad and duplicated } \\
\text { phalanges. } \\
\text { Facial: Midface hypoplasia, } \\
\text { low set ears, proptosis } \\
\text { cleft palate. } \\
\text { GIT: Ileal atresia, } \\
\text { caecal atresia }\end{array}$ & Father & Broad phalanges \\
\hline 10 & $\mathbf{M}$ & High & $\begin{array}{l}\text { GUT: Hydroureter } \\
\text { Facial: Accessory auricle }\end{array}$ & $\begin{array}{l}\text { Paternal } \\
\text { uncle }\end{array}$ & $\begin{array}{l}\text { Accessory } \\
\text { auricle }\end{array}$ \\
\hline 11 & $\mathrm{~F}$ & High & GUT: Cloaca & Mother & Septate vagina \\
\hline 12 & $\mathbf{F}$ & Low & $\begin{array}{l}\text { Skeletal: Toe webbing. } \\
\text { Facial: Facial asymmetry } \\
\text { CNS: Mental retardation } \\
\text { Misc: Hirsutism }\end{array}$ & $\begin{array}{l}\text { Brother } \\
\text { Mother }\end{array}$ & $\begin{array}{l}\text { Toe webbing } \\
\text { mental retardation } \\
\text { Mental retardation }\end{array}$ \\
\hline 13 & $\mathbf{M}$ & Low & $\begin{array}{l}\text { CVS: VSD } \\
\text { GUT: Shawl scrotum } \\
\text { Facial: Small lower face. } \\
\text { Misc: Umbilical hernia }\end{array}$ & Father & $\begin{array}{l}\text { Similar facial } \\
\text { configuration }\end{array}$ \\
\hline 14 & $\mathrm{~F}$ & Low & $\begin{array}{l}\text { GUT: Bifid vagina, } \\
\text { hydronephrosis }\end{array}$ & $\begin{array}{l}\text { Cousin (F) } \\
\text { Aunt }\end{array}$ & $\begin{array}{l}\text { Intact hymen } \\
\text { "Double uterus" }\end{array}$ \\
\hline 15 & $\mathbf{M}$ & High & $\begin{array}{l}\text { GUT: Hypospadias, bifid glans } \\
\text { Facial: "Odd facies". }\end{array}$ & Sister & $\begin{array}{l}\text { Similar facial } \\
\text { configuration }\end{array}$ \\
\hline
\end{tabular}

CVS $=$ Cardiovascular: $A S D=$ Atrial septal defect: $V S D=$ ventricular septal defect: TGV $=$ transposition of the great vessels: $A V=$ anterior-ventral: $G U T=$ genitourinary tract: GIT=gastrointestinal tract: $\mathrm{CNS}=$ central nervous system; Misc $=$ miscellaneous. 
these families the abnormality was a minor one and detailed examination of other family members might have yielded further cases, as in the family reported by Reid and Turner. ${ }^{6}$ Here 18 members over four generations had low ARM in association with minor thumb and ear anomalies. Such features, which may not have been recorded in the case notes of our study patients, could be of value as markers of autosomal dominant inheritance. Other reports of families with low ARM have suggested an autosomal recessive or sex linked recessive mode of inheritance. ${ }^{6-12}$

In our study familial cases associated with multiple abnormalities were heterogeneous (Table 3). In two cases there had been multiple abnormalities in siblings: case 6 had a low ARM with associated radial aplasia, major cardiac malformation, dysplastic kidneys, and pulmonary hypoplasia. A stillborn sibling with a low ARM also had an abnormal forearm, a single lower limb, and dysplastic kidneys. A further sibling had been anencephalic and another pregnancy resulted in an early miscarriage. Case 8 had a high ARM with vertebral abnormalities, a dysplastic foot, a major cardiac anomaly, and asplenia. A female sibling had a low ARM, polydactyly, a similar cardiac anomaly, and asplenia. In both families 6 and 8 , where no chromosome abnormality was detected, the conditions probably represent hitherto undescribed recessive syndromes.

In case 9 a high ARM was associated with broad and duplicated phalanges, a facial abnormality, and higher gut atresias. The child's father had similar malformations of the hands and feet but no apparent gut or facial anomaly. Case 10 had a high ARM with hydroureter and an accessory auricle. A paternal uncle also had an accessory auricle. In these two families autosomal dominant inheritance with reduced penetrance is a possibility.

Familial genitourinary abnormalities were seen in families 11 and 14. In the former the propositus had a cloaca and the mother an abnormal vagina. In case 14 the propositus had a low ARM with a bifid vagina and hydronephrosis and a female cousin and an aunt also had abnormalities of the genitalia.

We have described several inherited forms of ARM. Where the anomaly is associated with minor thumb and ear abnormalities, autosomal dominant inheritance may be implied ${ }^{7}$ and other family members should be carefully examined. In some cases of severe multiple abnormalities-for example, families 6 and 8-risk of recurrence is obviously high, but we have been unable to identify any consistent pattern to suggest autosomal recessive inheritance that would aid the genetic counsellor. Moreover, a search of the published works has not revealed any comparable cases, suggesting that such 'syndromes' are either unique to the individual families or very rare. We suggest that in families where a single case with ARM and multiple malformations occurs referral to a genetic clinic may be appropriate to establish if a rare syndrome diagnosis can be made, to discuss possible recurrence risks with the parents, and to inform them of any prenatal diagnostic tests that are available for future pregnancies.

We thank the paediatric surgeons and paediatricians in the North Western Region for access to case records.

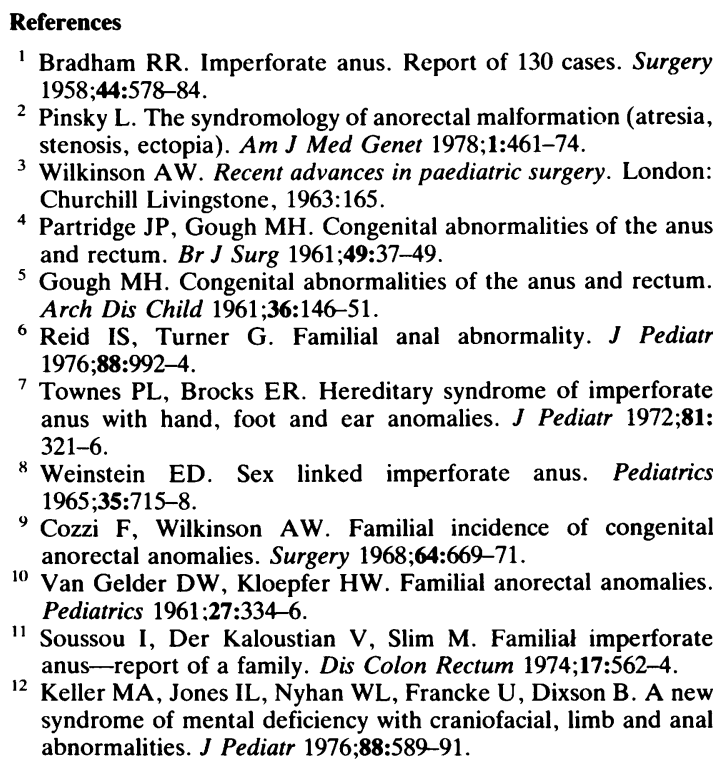

Correspondence to $\operatorname{Dr}$ G R Boocock, Booth Hall Children's Hospital, Blackley, Manchester, England.

Received 13 January 1987 